\title{
Properties of Concrete Containing Scrap-Tire Rubber
}

\author{
Mazyad Al-Fadhli ${ }^{*}$ and Jasem Alhumoud ${ }^{* *}$ \\ *( The Public Authority for Applied Education and Training,Kuwait, Email: maziad12@yahoo.com ) \\ **(Civil Engineering Department, College of Engineering and Petroleum, Kuwait University, Kuwait)
}

\begin{abstract}
Solid waste management is one of the major environmental concerns all over the world and in Kuwait. Over 5 billion tons of non-hazardous solid waste materials are generated in Kuwait each year. Of these, more than 2 million scrap-tires (approximately 2 million tons) are generated each year. In addition to this, about seven million scrap-tires have been stockpiled. Due to the increasingly serious environmental problems presented by waste tires, the feasibility of using elastic and flexible tire-rubber particles as aggregate in concrete is investigated in this study. Tire-rubber particles composed of tire chips, crumb rubber, and a combination of tire chips and crumb rubber, were used to replace mineral aggregates in concrete. These particles were used to replace $10 \%, 15 \%, 20 \%$, and $25 \%$ of the total mineral aggregate's volume in concrete. Cylindrical shape concrete specimens $15 \mathrm{~cm}$ in diameter and $30 \mathrm{~cm}$ in height were fabricated and cured. The fresh rubberized concrete exhibited lower unit weight and acceptable workability compared to plain concrete. The results of a uniaxial compressive strain control test conducted on hardened concrete specimens indicate large reductions in the strength and tangential modulus of elasticity. A significant decrease in the brittle behavior of concrete with increasing rubber content is also demonstrated using nonlinearity indices. The maximum toughness index, indicating the post failure strength of concrete, occurs in concretes with $25 \%$ rubber content. Unlike plain concrete, the failure state in rubberized concrete occurs gently and uniformly, and does not cause any separation in the specimen. Crack width and its propagation velocity in rubberized concrete are lower than those of plain concrete. Ultrasonic analysis reveals large reductions in the ultrasonic modulus and high sound absorption for tire-rubber concrete.
\end{abstract}

\section{INTRODUCTION}

More than 2 million scrap-tires are produced in Kuwait each year (Rubber Manufacturers Association, 2000). In addition to this, more than seven million tires are currently stockpiled in Rhayyah northern of Kuwait (Rubber Manufacturers Association, 2000). These stockpiles are dangerous not only due to potential environmental threat, but also from fire hazards and provide breeding grounds for rats, mice, vermines and mosquitoes (Khatib and Bayomy, 1999; Guneyisi et al., 2004 Eldin and Senouci, 1993, 1994; Toutanji, 1996; Fedroff et al., 1996; Topcu, 1995; Siddiquel and Naik, 2004; Hernandez-Olivares et al., 2002; Ghaly and Cahill, 2005; Li et al., 2004). Actually, in 2012 a fire broke out in the dumpsite. Hundreds of firefighters from six stations as well as soldiers and employees of the Kuwait Oil Company (KOC) tool parts in the efforts to extinguish the blaze. Over the years, disposal of tires has become one of the serious problems in environments. Landfilling is becoming unacceptable because of the rapid depletion of available sites for waste disposal. For example France, which produces over 10 million scrap-tires per year, will have a dwindling supply of landfills starting from July 2002, due to a new law that forbids any new landfill in the country. Used tires are required to be shredded before landfilling. The importance of recycling of waste tires coupled with the interest in overcoming the aforementioned concrete defects have motivated a significant body of research pertaining to rubberized concrete. Properties, testing, and design of rubber as an engineering material were investigated in 1960 (Eldin and Senouci, 1993). Eldin and Senouci (1993, 1994) used tire-rubber particles as concrete aggregates, elucidating rubberized concrete properties, and proposed an analytical approach to predict the strength in rubberized concrete. Khatib and Bayomy (1999) studied rubberized Portland cement concrete and offered some practical uses of rubberized concrete, including reduction factors. Their paper contains limitations and concerns of using tire-rubber concrete as well. Li et al. (2004) used waste tires in the form of fibers and developed waste tire fiber modified concrete. The static and dynamic behavior of recycled tire-rubber-filled concrete was investigated by Hernandez-Olivares et al. (2002). Siddiquel and Naik (2004) presented an overview of research published on the use of scrap tires in Portland cement concrete. Guneyisi et al. (2004) investigated the properties of rubberized concretes containing silica fume through six designated rubber contents. These previous findings reveal that the properties of rubberized 
concrete are affected by type, size, content, and the procedure of incorporating the rubber into the concrete.

A tire is a composite of complex elastomer formulations, fibers and steel/fiber cord.
Tires are made of plies of reinforcing cords extending transversely from bead to bead, on top of which is a belt located below the thread. Table 1 lists typical types of materials used to manufacture tires.

Table 1.Typical materials used in manufacturing tire (Rubber Manufacturer's Association, 2000)
1. Synthetic rubber
2. Natural rubber
3. Sulfur and sulfur compounds
4. Phenolic resin
5. Oil
(i) Aromatic
(ii) Naphthenic
(iii) Paraffinic
6. Fabric
(i) Polyester
(ii) Nylon
7. Petroleum waxes
8. Pigments
(i) Zinc oxide
(ii) Titanium dioxide
9. Carbon black
10. Fatty acids
11. Inert materials
12. Steel wires

In this paper, tire-rubber concrete properties are investigated using mechanical and non-destructive testing for different sizes of tire particles. The experimental observations and subsequent explanations of tire-rubber concrete behavior under compressive strain are presented. Ultrasonic analysis investigates sound absorption and the ultrasonic modulus of tire-rubber concrete.

\section{EXPERIMENTAL PROGRAM}

Concrete cubes with dimensions of $100 \times 100 \times 100 \mathrm{~mm}^{3}$ were prepared and tested for their compressive strength. The design compressive cube strength was prepared according to Neville (1981) for plain concrete specimen equals $40 \mathrm{MPa}$. Types of concrete mixes used in this study are shown below:

Type I Control Mix Made with Normal coarse and fine aggregates. Eighteen cubes used. (without any tire rubbers)

Type II Coarse Aggregates replacement with coarse tire rubbers with the percentages $10 \%, 15 \%, 20 \%$, and $25 \%$. Seventy two cubes used. (Normal fine aggregates is used in this mix type)

Each reading was taken as the average of 3 test results. This brings the total number of test specimen to 234 cubes in addition to 13 setting times, 13 slump tests and 13 initial and final setting times.

\section{PROPERTIES OF MATERIALS 3.1 WASTE RUBBER}

Tire-rubbers has been employed in concrete mixes. The proportions of the various chemical constituents of the tire rubbers has been presented earlier in table 1 .

\subsection{CONCRETE MIX}

The concrete mix for the control specimens have been designed according to Neville (Neville 1981). The mix proportions are shown in table 1. Using these mix proportions, percentages of fine and coarse aggregates have been replaced withscrap tire-rubber particles with proportions as previously indicated.Constituent materials for concrete mixes included a Type I Portland cement meeting ASTM C150 requirements, crushed stone gravel with a maximum size of $20 \mathrm{~mm}$ as a coarse aggregate, natural sand with a $4.75 \mathrm{~mm}$ maximum size as fine aggregate, and tire-rubber particles Tire 
particle specifications are summarized in Table 1. These specifications were provided by tire manufacturers according to ANSI (American
National Standard Institute) tests. One type of scrap tire-rubber particles were used: that is coarse tire chips produced by mechanical shredding.

Table 2. Properties of the different concrete mixes

\begin{tabular}{|c|c|c|c|c|}
\hline Data & $\begin{array}{c}10 \% \text { Rubber } \\
(\mathrm{kg})\end{array}$ & $\begin{array}{c}15 \% \text { Rubber } \\
(\mathrm{kg})\end{array}$ & $\begin{array}{c}20 \% \text { Rubber } \\
(\mathrm{kg})\end{array}$ & $\begin{array}{c}25 \% \text { Rubber } \\
(\mathrm{kg})\end{array}$ \\
\hline Rubber weight & 1.13 & 1.70 & 2.26 & 2.82 \\
\hline Cement & 6.40 & 6.40 & 6.40 & 6.40 \\
\hline Water & 3.07 & 3.07 & 3.07 & 3.07 \\
\hline Sand & 10.18 & 9.60 & 4.05 & 4.20 \\
\hline $\begin{array}{c}\text { Coarse } \\
\text { aggregate } 3 \backslash 4\end{array}$ & 4.20 & 4.20 & 6.60 & 6.60 \\
\hline $\begin{array}{c}\text { Coarse } \\
\text { aggregate } 1 \backslash 2\end{array}$ & 6.60 & 6.60 & 6.60 & 6.60 \\
\hline $\begin{array}{c}\text { Coarse } \\
\text { aggregate } 3 \backslash 8\end{array}$ & 6.60 & 6.60 & 0.48 & 0.48 \\
\hline W/C & 0.48 & 0.48 & & \\
\hline
\end{tabular}

Tire particles were not pretreated before their incorporation into the concrete mixture. The properties of fine and coarse aggregates were determined according to ASTM standard test methods C127, C128, C129, and C136. The grading of tire-rubber materials was determined based on the ASTM C136 method. The grading curve of rubber materials was determined by using crushed stones in each sieve in order to provide adequate pressure on tire-rubber particles to pass the sieves. Grading curves are presented in figures 1 to 6. Data regarding the properties of the aggregates and the rubber particles are given in Table 2. The specific gravity of the cement was evaluated to be $3.15 \mathrm{~g} / \mathrm{cm}^{3}$.

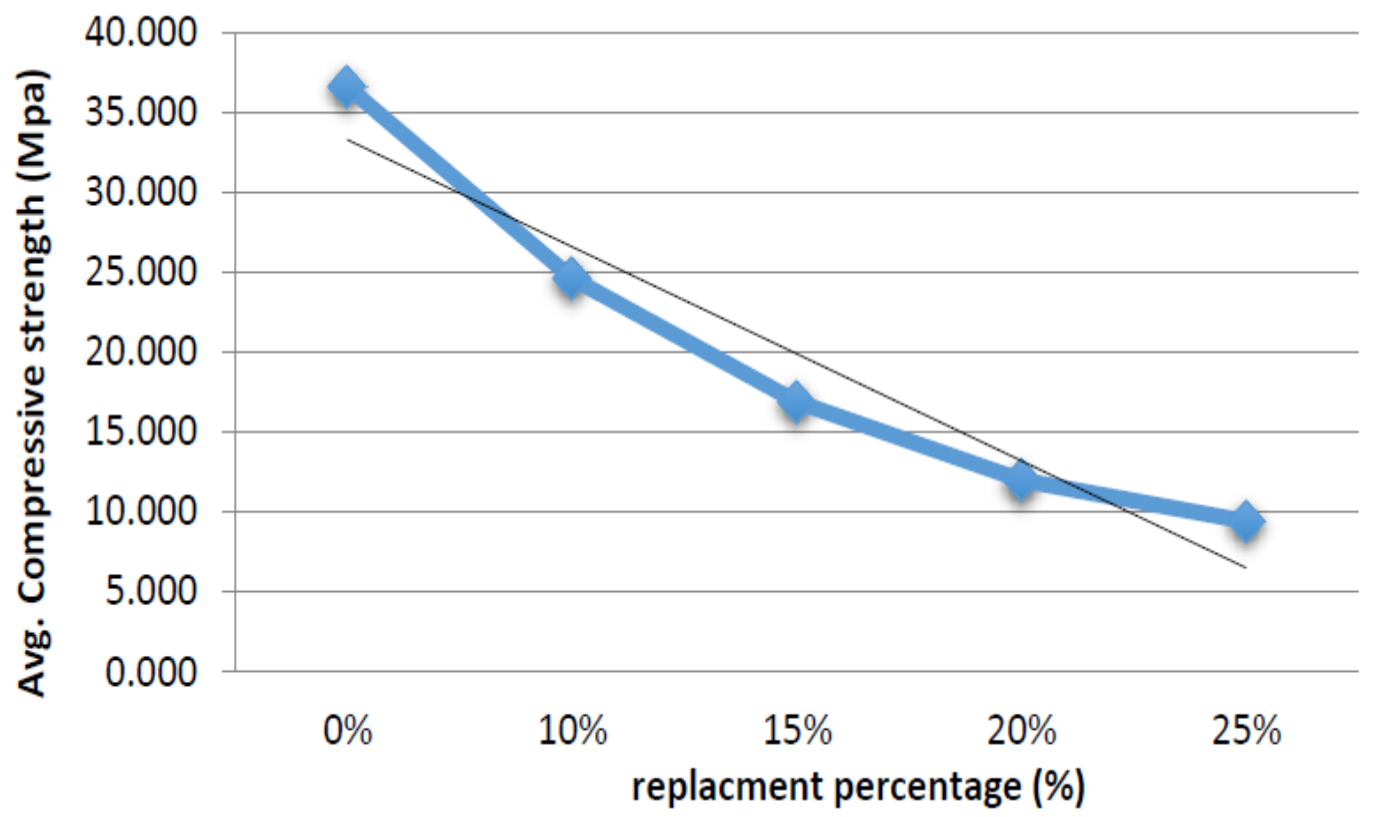

Figure 1.Average compressive strength for all specimens after 7 days. 


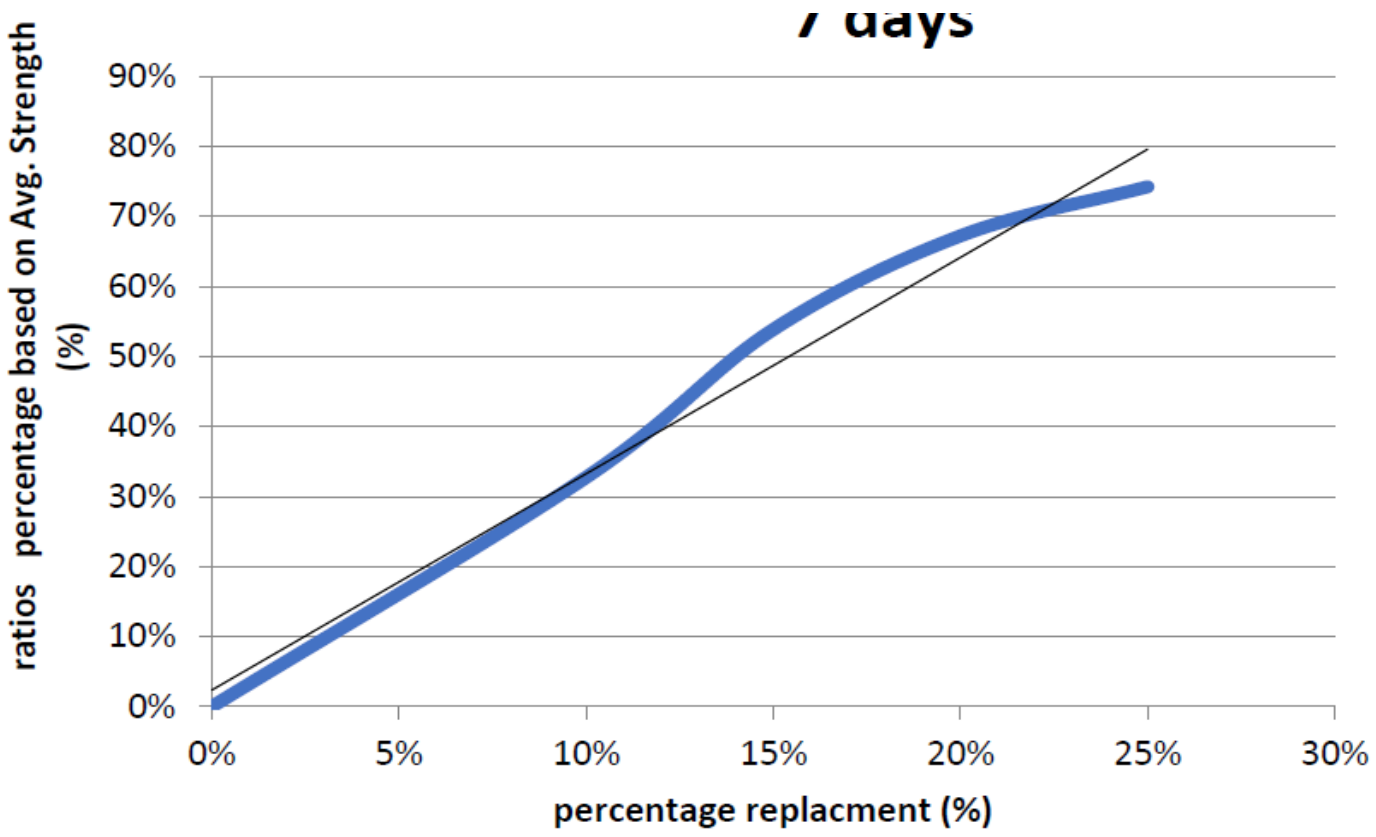

Figure 2. Ratio percentages for all specimens after 7 days.

To evaluate the properties of fresh concrete, slump andunit weight were measured according to ASTM C143 andASTM C138 (ASTM, 1988), respectively. A compressivestraincontrol test was conducted for hardened concretespecimens to obtain the stress-strain curves for all of thespecimens. The test was performed by a universal testingmachine and a sensitive data acquisition system. Themachine yielded a loading value variation due to a constantrate of specimen deformation. This rate was chosen to be $0.005 \mathrm{~mm} / \mathrm{sec}$.

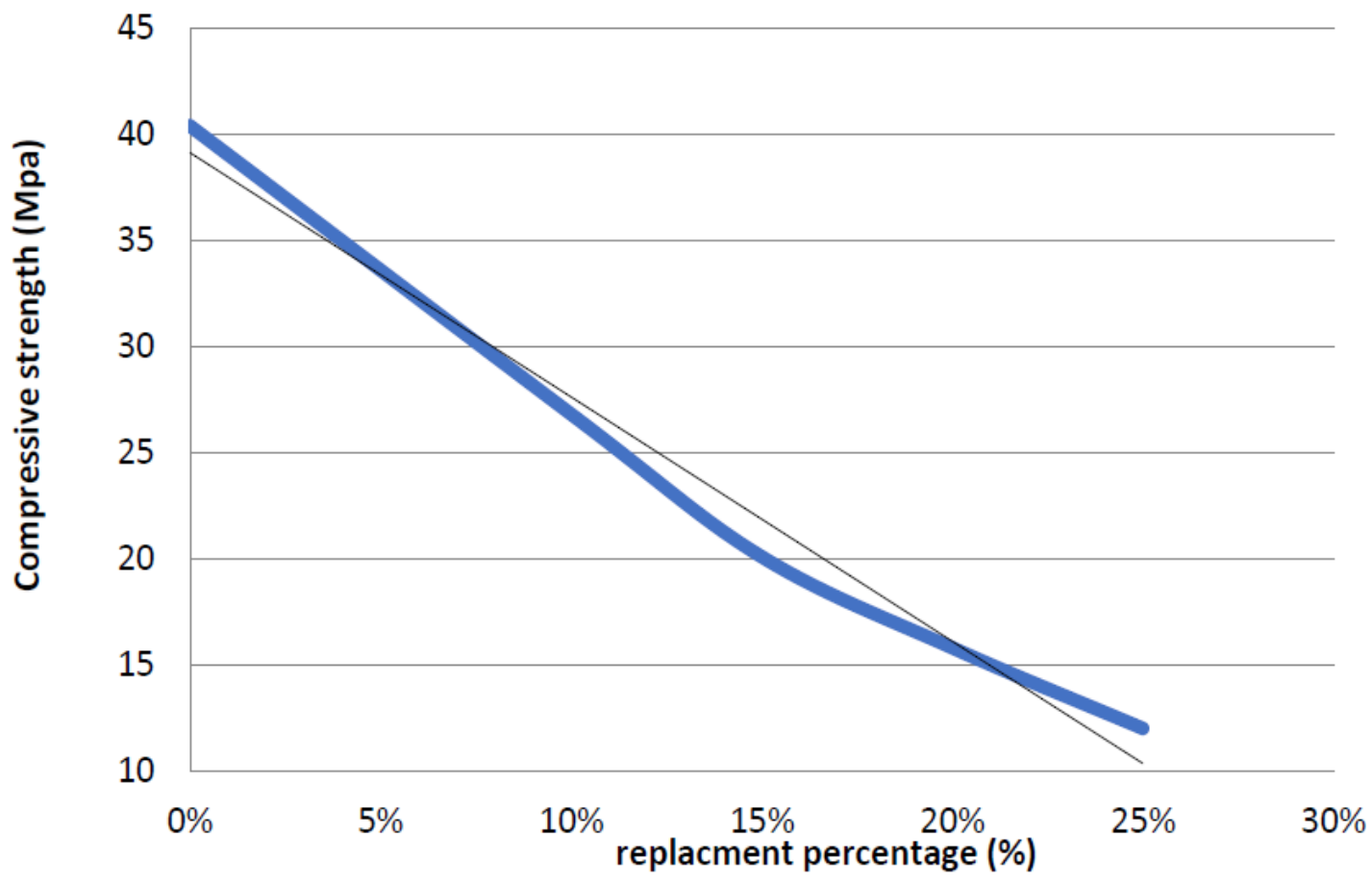

Figure 3. Average compressive strength for all specimens after 7 days. 


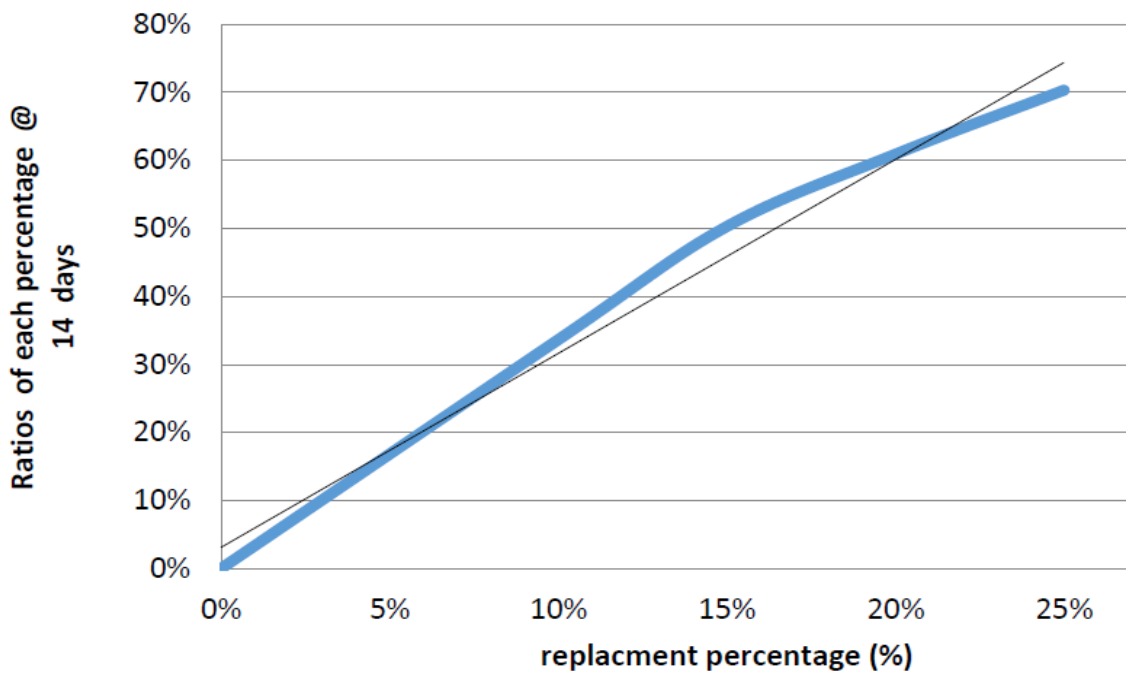

Figure 4. Ratio percentages for all specimens after 14 days.

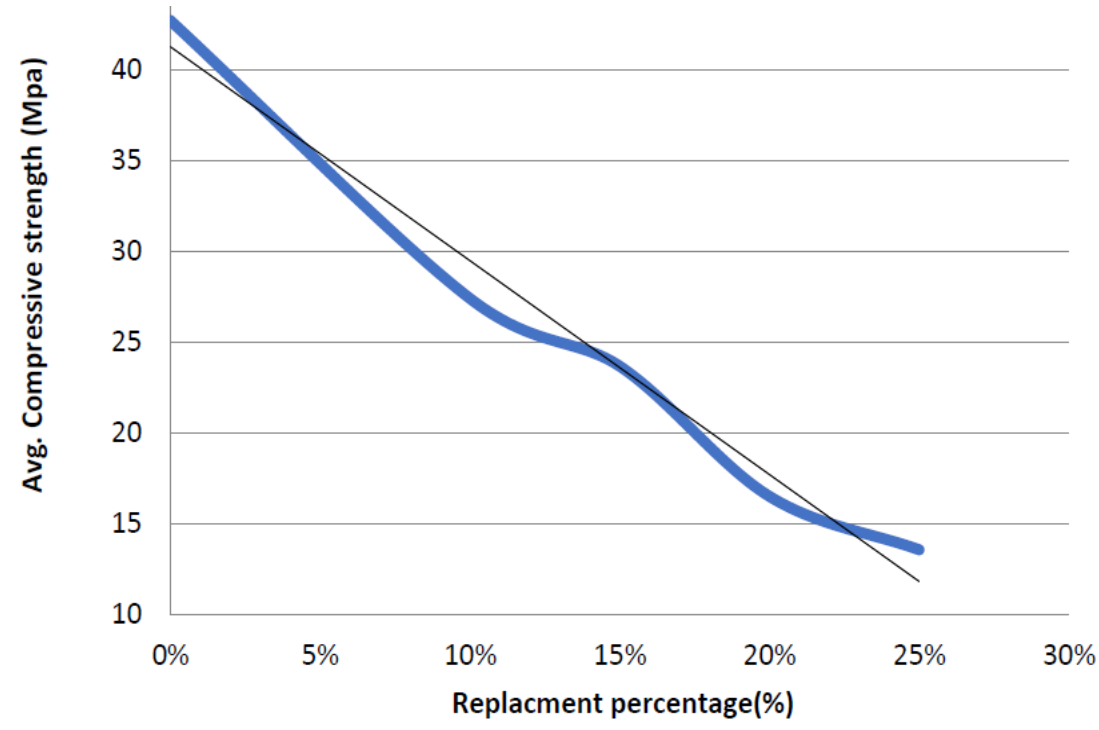

Figure 5. Average compressive strength for all specimens after 28 days.

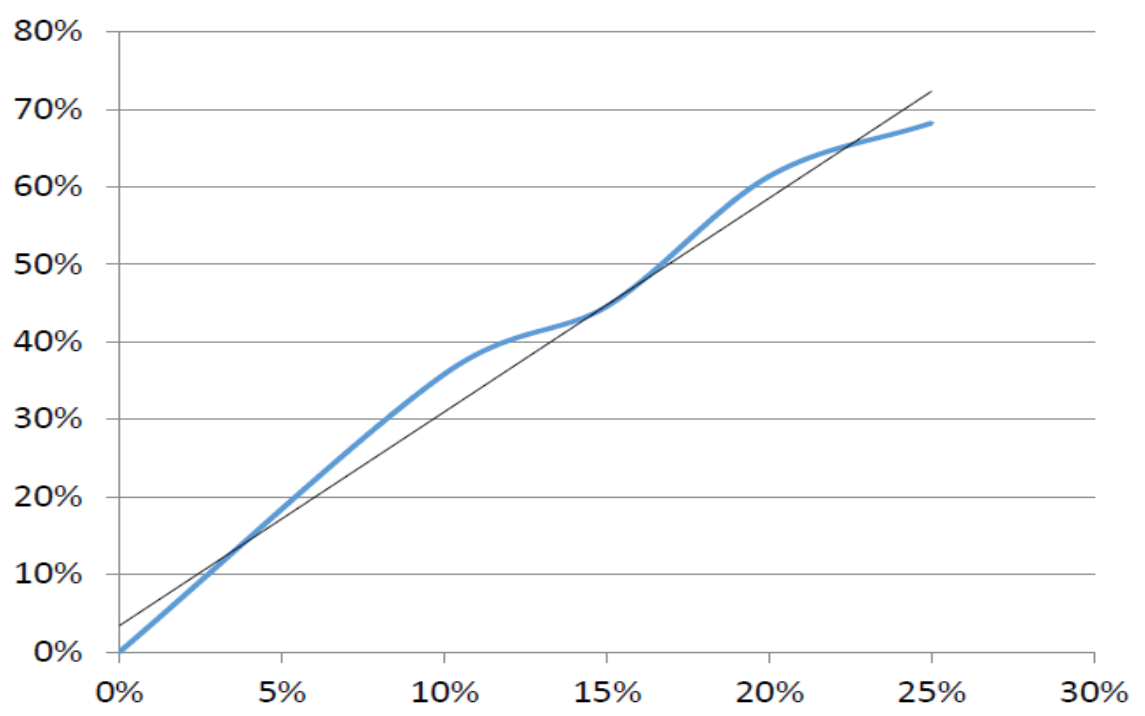

Figure 6. Ratio percentages for all specimens after 28 days. 
To evaluate the properties of fresh concrete, slump andunit weight were measured according to ASTM C143 andASTM C138 (ASTM, 1988), respectively. A compressivestrain-control test was conducted for hardened concretespecimens to obtain the stress-strain curves for all of thespecimens. The test was performed by a universal testingmachine and a sensitive data acquisition system. Themachine yielded a loading value variation due to a constant rate of specimen deformation. This rate was chosen to be 0.005 $\mathrm{mm} / \mathrm{sec}$.

Table 3. Slump test and air content for the different specimens.

\begin{tabular}{|c|c|c|}
\hline replacement percentage & Slump test(mm) & Air content (\%) \\
\hline $0 \%$ & 45 & $2 \%$ \\
\hline $10 \%$ & 97 & $3 \%$ \\
\hline $15 \%$ & 49 & $2.50 \%$ \\
\hline $20 \%$ & 50 & $2.50 \%$ \\
\hline $25 \%$ & 46 & $3.60 \%$ \\
\hline
\end{tabular}

Variations of slump and unit weight of fresh concretewith respect to tire aggregate concentration are presentedin Table 3. The workability, defined as the ease with whichconcrete can be mixed, transported, and placed, of freshconcrete is affected by the interactions of tire particlesand mineral aggregates. As shown in table 3 , the slumpfor $\mathrm{F}$ mixes increased with tire aggregate concentrationslower than $15 \%$, and reached a maximum value when thetire aggregate concentration was $15 \%$. Tire aggregate concentrationsexceeding $15 \%$ reduced the slump. The slumpfor $\mathrm{C}$ mixes decreases to a minimum value with tire aggregateconcentrations of $15 \%$. The slump fluctuates slightlyover the minimum value for tire aggregate concentrationsexceeding $15 \%$. Slump reduction for combined mixes wasless than that of $\mathrm{C}$ mixes. In general, the rubberized concretespecimens have acceptable workability in terms ofease of handling, placement, and finishing. As shown intable 3, the ordinary procedure for evaluating the slumpof the investigated mixes does not support the actual stateof the mix workability. These findings suggest that anothermethod is required to properly measure the slump of rubberizedconcrete (Eldin and Senouci, 1994).The unit weight of the concrete ranged from 2409 to1324 $\mathrm{kg} / \mathrm{m}^{3}$, depending on rubber content. Increasing therubber content reduces the unit weight of the concrete, resulting in lighter concretes. The unit weights of the C,F, and CF mixes were reduced $45 \%, 34 \%$, and $33 \%$, respectively,compared to plain concrete. The unit weight reductionis a result of the lower unit weight of tire-rubberparticles replacing the much heavier mineral aggregates.Thus, rubber-tire concrete could be used wherever lightweightconcrete is required. For example, tire-rubber concretecontaining low tire-rubber concentrations can beused in structures to reduce earthquake damage. Due tothe high water absorption of tire particles, the ratio ofthe fresh concrete unit weight to the hardened unit weightin tire-rubber concrete is greater than that of plain concrete.Therefore, tire-rubber concrete is expected to bemore porous than plain concrete. A smaller reduction inunit weight, compared to that of the $\mathrm{F}$ and $\mathrm{CF}$ mixes, was realized for $\mathrm{C}$ mixes with rubber concentrations lowerthan $40 \%$. At higher concentrations, the result is reversed.

\section{CONCLUSIONS AND RECOMMENDATIONS.}

The increase in the awareness of waste management and environment-related issues has led to substantial progress in the utilization of waste/by-products like tire-rubber. This paper has presented various aspects on tire-rubber and its usage in concrete, which could be summarized and concluded as:

1. Fresh rubberized concrete mixtures with increasing rubber concentrations present lower unit weights compared to plain concrete. Workability of rubberized concrete with coarse rubber particles is reduced with increasing rubber concentration; however, rubberized concrete with fine rubber particles exhibits an acceptable workability with respect to plain concrete.

2. The substitution of mineral aggregates with tire-rubber particles in concrete results in large reductions in ultimate strength and the tangential modulus of elasticity. Due to the considerable decrease in ultimate strength, rubber concentrations exceeding $25 \%$ are not recommended. Pretreatment of tire particle surfaces should be considered for possible improvement of tire-rubber concrete mechanical properties. An investigation is needed to identify the influence of rubber's mechanical properties on the ultimate strength of rubberized concrete.

3. As the percent of waste crumb tire replacement increases, Compressive strength decreases.

4. As the percent of waste crumb tire replacement Increases, Density decreases.

5. As increasing waste crumb tires replacement percentage from $0 \%-25 \%$ by ratio $5 \%$ for each mix, the Slump test results showed no significant change, so all mixes are close to each other in consistency. 
6. The density and unit weight of mixes are decreasing as the replacement Percentage increasing.

7. As increasing waste crumb tires replacement percentage from $0 \%-25 \%$ by ratio $5 \%$ for each mix, air content is increasing also.

8. Modulus of elasticity decreases as waste crumb tires replacement Increases.

This study has exclusively focused on the mechanical and physical properties of tire-rubber concrete for rubber replacements of mineral aggregates. There is a need for future studies to investigateenergy absorption of tire-rubber concrete under dynamicloading, and also the durability of tire-rubber concreteunder adverse weathering conditions.

\section{REFERENCES}

[1]. Albano, C. et al., 2005. Influence of scrap rubber addition to Portland I concrete composites: destructive and non-destructive testing. Compos. Struct. 71, 439-446.

[2]. American Concrete Institute, 2002, Standard practice for selecting proportions for normal, heavyweight and mass concrete, Document No: ACI 211.1-91.

[3]. ASTM, 1988, Concrete and Aggregate, Annual Book of ASTM Standards, vol. 04.02, Philadelphia.

[4]. Eldin, N.N., Senouci, A.B., 1993. Rubbertire particles as concrete aggregate. J. Mater. Civil. Eng. 5 (4), 478-496.

[5]. Eldin, N.N., Senouci, A.B., 1994. Measurement and prediction of the strength of rubberized concrete. Cement Concrete Compos. 16, 287-298.

[6]. Fedroff, D., Ahmad, S., Savas, B.Z., 1996. Mechanical properties of concrete with ground waste tire rubber, Transportation Research, Record No. 1532, Transportation Research Board, Washington DC.

[7]. Ghaly, A.M., Cahill, J.D., 2005. Correlation of strength, rubber content and water: cement ration in rubberized concrete. Can. J. Civil Eng. 32,1-7.

[8]. Guneyisi, E., Gesoglu, M., Ozturan, T., 2004. Properties of rubberized concretes containing silica fume. Cement Concrete Res. V 34, 2309- 2317.

[9]. Hernandez-Olivares, F., Barluenga, G., Bollati, M., Witoszek, B., 2002. Static and dynamic behavior of recycled tire rubberfilled concrete. Cement Concrete Res. 32, $1587-1596$.
[10]. Khatib, Z.K., Bayomy, F.M., 1999. Rubberized Portland cement concrete. ASCE J. Mater. Civil. Eng. 11 (3), 206-213.

[11]. Li, G., Garrick, G., Eggers, J., Abadie, C., Stubblefield, M.A., Pang, S., 2004. Waste tire fiber modified concrete. J. Compos. B (35), 305-312.

[12]. Neville, A.M., 1995. Properties of Concrete, fourth ed. Longman, London.

[13]. Segre, N., Joekes, I., 2000. Use for tire rubber particles as addition to cement paste. Cement Concrete Res. 30 (9), 1421-1425.

[14]. Siddiquel, R., Naik, T.R., 2004. Properties of concrete containing scrap tire rubber - an overview. Waste Manage. 24, 563-569.

[15]. Topcu, I.B., 1995. The properties of rubberized concretes. Cement Concrete Res. 25 (2), 304-310.

[16]. Toutanji, H.A., 1996. The use of rubber tire particles in concrete to replace mineral aggregates. Cement Concrete Compos. 18, 135-139. 